\title{
Multiple Publications From the Same Dataset: Is It Acceptable?
}

In recent years, the "publish or perish" approach has forced the academic environment and academics to give importance to quantity rather than quality. The rapid increase in the number of academic journals and publications in today's world brings about an increase in publication ethics violations.

One of the consequences of this trend has been the production of multiple publications from the same dataset. This issue cannot be discussed without mentioning research integrity, transparency, and ethical violation. However, there is no consensus on whether producing more than one publication from the same dataset is an ethical violation. This situation may be a violation of ethics and could prevent the publication of many articles that would contribute to the scientific literature, due to the fear of ethical violations. In this editorial, we discuss the issues and related definitions to consider when generating multiple publications from the same dataset.

It would make sense to start with the definitions of 2 important terms related to this topic; Duplicate (Redundant) and salami publications. The International Committee of Medical Journal Editors (ICMJE) defines a duplicate publication as "the publication of a paper that overlaps substantially with one already published, without clear, visible reference to the previous publication." Salami slicing or a salami publication involves segmenting a large study into 2 or more publications. These segments are referred to as "slices" of a study. ${ }^{2,3}$ The simplest example for slicing would be the publication of the results of a research based on gender and age group.

Salami slicing is considered an ethical violation in scientific publishing and may result in significant sanctions. However, it may be planned to produce more than one publication if a dataset contains multiple sub-datasets, or if the project outputs are too large to be reported in a single publication, or if the research has a secondary finding that was not discussed in the first article. ${ }^{4}$ From a largescale study, one article containing the initial outputs and one or more other articles reporting the secondary analysis may be produced. In this case, the authors cannot be expected to produce only one article from all the data obtained from a single study. In fact, not sharing scientifically important research results with the scientific world due to the fear of salami slicing may pose an ethical problem. ${ }^{5}$ For example, the medical world needed all kinds of information about the COVID-19 pandemic that has shaken the world recently. All data coming out of the city of Wuhan, where the epidemic started, were important for humanity. The scientific world needed data on symptomatology, transmission, treatment methods, and in-hospital and short-term prognosis from the same patient records. Arab-Zozani et al., in their analysis, noted that in just 2.5 months, more than 3000 articles about COVID-19 were accepted by journals. ${ }^{6}$ Refraining from producing other articles because an article had already been produced from these data would have blocked access to information that was very important for humanity. Therefore, researchers may produce more than one publication from the same dataset which they consider important for science and which would not disrupt the integrity of the research.

When you have to publish your data in more than one article, how can it be done without compromising the integrity of the research? In this case, it is important to know some points in order to avoid ethical violations.

It is most important that the authors are transparent and clearly state the reasons for this to the editor of the relevant journal. In other words, authors should share their previous work with the editors transparently and state this situation in the article. Another important factor is to ensure that these manuscripts are unique. In order to ensure the uniqueness of your second paper from the same dataset, you should consider the criteria outlined in Table 1. ${ }^{7}$

In addition to these 2 important points mentioned above, authors should pay attention to the following points in order to avoid bias in the editorial evaluation and peer-review process and to avoid ethical violation investigations after the article has been accepted. . $^{1,5,-10}$

- The cover letter should clearly inform the editor that there is a previous article on the same subject. The full text of the previously published article should be forwarded to the editor, and if possible, other studies planned on this subject should also be mentioned.

- The cover letter should also inform the editor regarding the titles specified in Table 1, including the similarities/differences between the 2 articles.

- The previous study should be clearly stated in the article and the previous study should be referenced. While doing this, it would be more appropriate to indicate the previous publication in the text and the bibliography as "anonymous" until the peer-review process is over, to avoid influencing the peer-review process of the article.

Corresponding author: Zafer Koçak, Editor-in-Chief, Balkan Medical Journal Department of Radiation Oncology, Trakya University School of Medicine, Edirne, Turkey

e-mail: zaferkocak12@gmail.com

- DOI: $10.5152 /$ balkanmedj.2021.21008

Available at www.balkanmedicaljournal.org

ORCID iDs of the authors: S.A. 0000-0001-7112-3970; Z.K. 0000-0003-1918-7795.

Cite this article as:

Altay S, Koçak Z. Multiple publications from the same dataset: Is it acceptable? Balkan Med J. 2021;38(5):263-264

Copyright@Author(s)-Available online at http://balkanmedicaljournal.org/ 
TABLE 1. Some Factors to Consider as Uniqueness Criteria for Publishing Multiple Articles from the Same Dataset*

- Research question: What is the main question to be answered in the research?

- Theories: What are the theories and/or methods used in the research?

- Variables: Which dependent and independent variables were used in the research?

- Theoretical implications: What are the main conclusions of the researchers from the study?

- Managerial implications: What do the results of the study suggest for clinical practice?

*Modified from the article by Kirkman et al. ${ }^{7}$

- If the first and the main article belonging to the same database are in the submission process, if possible, it would be more appropriate not to send a second article to a journal before the evaluation process of the first article is completed.

- The author of the article should state why the second publication is needed, and what the new article adds to the previous article.

- All variables analyzed in the first publication should be included in the analyses to ensure consistency between articles.

- If a change has been made in an existing measurement or method in the previous article, the reason for this must be explained in the following study.

The fact that authors do not prefer to be transparent increases the risks of encountering ethical violation issues. Today, with the development of similarity-scanning programs, it has become easier to reveal cases of scientific misconduct. On the other hand, if the study includes the criteria that we have tried to explain above, it would not be wrong to encourage the authors to publish more than one article using a single data set. The key issue, as the ICMJE points out, is the attitude of researchers toward transparency and research integrity.

\section{Servet Altay ${ }^{1}$, Zafer Koçak $^{2}$ (D)}

${ }^{1}$ Department of Cardiology, Trakya University School of Medicine, Edirne, Turkey

${ }^{2}$ Editor-in-Chief, Balkan Medical Journal Department of Radiation Oncology, Trakya University School of Medicine, Edirne, Turkey

\section{REFERENCES}

1. International Committee of Medical Journal Editors (ICMJE). Available at: http:// www.icmje.org/recommendations/browse/publishing-and-editorial-issues/overlappin g-publications.html. Accessed August 6, 2021.

2. Abraham P. Duplicate and salami publications. J Postgrad Med. 2000;46(2):67-69.

3. Office of Research Integrity. Salami Slicing (i.e., data fragmentation). Available at: [CrossRef]. Accessed August 6, 2021.

4. Beaufils P, Karlsson J. Legitimate Division of Large Datasets, salami slicing and dual publication. Where does a Fraud Begin? Orthop Traumatol Surg Res. 2013;99(2):121122. [CrossRef]

5. Gündüz T, Akademik Yazımda Bir Araştırmadan Birden Fazla Yayın Üretmek: Etik Bir Problem (mi?) Uludağ Univ İlahiyat Fak Derg. 2020;29(1):45-80.

6. Arab-Zozani M, Hassanipour S. Features and limitations of LitCovid hub for quick access to literature about COVID-19. Balkan Med J. 2020;37(4):231-232. [CrossRef]

7. Kirkman BL, Chen G. Maximizing your data or data slicing? Recommendations for managing multiple submissions from the same dataset. Manag Organ Rev. 2011;7(3):433-446. [CrossRef]

8. Norman I, Griffiths P. Duplicate publication and 'salami slicing': Ethical issues and practical solutions. Int $J$ Nurs Stud. 2008;45(9):1257-1260. [CrossRef]

9. Watson R, Pickler R, Noyes J, et al. How many papers can be published from one study? J Adv Nurs. 2015;71(11):2457-2460. [CrossRef]

10. Tolsgaard MG, Ellaway R, Woods N, Norman G. Salami-slicing and plagiarism: How should we respond? Adv Health Sci Educ Theory Pract. 2019;24(1):3-14. [CrossRef] 